course and we hope to use it in our classes in the Fall of 1977, although for an advanced approach to the engineering aspects the more specialized books of Middleman and Lightfoot are still preferable or at least supplementary to this one.

Our only serious reservation is the cost of the book, especially considering the form of printing undertaken by this publisher. The price is unacceptable for an undergraduate textbook, although the prepublication announcement that we received earlier this year, stated that "a special discount for adoption orders of five or more copies is available," at the price of $\$ 24.50$.

Nrcholas A. Peppas Sc.D. Assistant Professor and Robert E. HannemanN, M.D. Visiting Professor School of Chemical Engineering Purdue University

Thermodynamics for Chemical Engineers, K. E. Betts, J. S. Rowlinson, and G. Saville. The MIT Press, Cambridge, Massachusetts, 1975, 505 pages. $\$ 19.95$.

This book provides a thorough introduction to the subject. The first eight chapters develop the relations that are utilized in classical thermodynamics while the final chapter treats the prediction of thermodynamic properties by means of statistical thermodynamics. Although the authors state that the text is used throughout the three years of undergraduate study in England, it could be covered in a two-term juniorlevel course. The authors introduce numerous exercises throughout the text and these should provide some of the practice that is so necessary in learning the subject. The book utilizes the SI system of units throughout. The cautions and calculation strategies included in this book are particularly helpful. Careful attention to these cautions should enable the reader to avoid some of the common misapplications of the subject.

The book does not contain the property table for any common substance as most thermodynamics texts do. It does provide an extensive bibliography of these charts, however.

This carefully written book could serve not only as an introduction to the subject, but also as a reference for those familiar with the subject.

Alan J. Brainard Department of Chemical and Petroleum Engineering University of Pittsburgh
Gas Dynamies, Vol. 1, by M. J. Zuerow and J. D. Hoffman, John Wiley \& Sons, 1976, 772 pages. $\$ 26.95$.

This text has its origin in Zucrow's earlier book Aircraft and Missile Propulsion, Vol. I, Thermodynamics of Fluid Flow and Application to Propulsion Engines, and represents an updated version of that work based on the extensive classroom experience of Professor Hoffman. Use of numerical methods for solving real gas dynamics problems is emphasized.

The text begins with two chapters covering fundamental principles, and the derivation of the governing equations for compressible flow. Here one finds that modern fluid mechanics has been completely avoided in the presentation of the laws of mechanics, and all of the recent progress in thermodynamics has been ignored. The concepts of kinematics and stress are presented in a superficial, and sometimes incorrect, manner.

After having dispensed with fundamentals, the authors move into home territory with four chapters on onedimensional flow covering general features, area change, friction, and heat transfer. Virtually every aspect of onedimensional flow is discussed here, and in these chapters one finds numerous solved example problems. A significant number of these deal with the use of numerical methods for solving various compressible flow problems.

Completion of the material on onedimensional flow finds one halfway through the text and moving on to shock waves (normal and oblique), expansion waves, and combustion waves. These three chapters are directed toward the analysis of supersonic propulsion systems, and once again there are numerous solved example problems to illustrate the application of various theoretical developments. The material contained in these first nine chapters is presented within the framework of one-dimensional flows, and in Chapter 10 one is introduced to the general features of multidimensional Hows. This is followed with chapters on acoustics and twodimensional irrotational supersonic flow. The final chapter takes up the matter of unsteady, one-dimensional, homentropic flows, with much of the chapter devoted to numerical methods.

While one cannot expect to find in this text a rigorous theoretical treatment of gas dynamics, the authors possess a weath of knowledge about compressible flow and they have presented this clearly and in great detail.

STEPHEN WHITAKER

Dept. of Chemical Engineering University of California Davis, California
Order In Polymer Solutions, edited by K. Sole of Midland Macromolecular Institute (MMI), Gordon and Breach, 1976, 320 pages, $\$ 19.50$

This book consists of 13 papers presented at the Ist monotopical symposium held at MMI. All the papers including several authoritative reviews and new theoretical and experimental results deal primarily with the presence of ordered structure, helix formation, solvation and association in both synthetic and biological polymers in solution. Furthermore, since subjects are current and sufficiently integrated with one another so that any chemical engineer who is at all interested in the effects of order on reaction efficiency, mechanism, rates, as well as the properties of such products will find this book a welcome addition to his personal library.

For example, as one who is primarily interested in order in the so-called "amorphous" solid state, I find the evidence described by G. Challa on the stereospecific replica polymerization of methyl methacrylate on stereoregular poly (methyl methacrylate) as a polymer matrix in different types and on their replication efficiency highly interesting. I won't hesitate in recommending this book to my fellow chemical engineers who are interested in polymers.

G. S. Y. YEH

Departments of Chemical Materials and

Metallurgical Engineering The University of Michigan

\section{CHEMICAL REACTION ENGINEERING}

\section{Proceedings of}

4th International/6th European Symposium Heidelberg/FRG, 6-8 April 1976

sponsored by The American Institute of Chemical Engineers, the American Chemical Society, the Canadian Society for Chemical Engineering and the European Federation of Chemical Engineering.

9 survey papers, 45 contributed papers by authors from the USA and Europe. Volume of 660 pages including graphs and tables, 660 pages DIN A 5 , offset print of manuscripts. Cost: DM 100-plus DM 6.80 packing and surface mail or plus DM 16-packing and airfreight.

Available from DECHEMA, P.O.B. 9701 46, D 6000 Frankfurt 97, F.R.G. 